\title{
Inhibition of Hydrocyanic Acid Evolution from Polyurethanes during Oxidative Degradation*
}

\author{
H. H. G. JellineK, A. Chaudhuri, ${ }^{* *}$ and K. TAKadA*** \\ Department of Chemistry, Clarkson College of Technology, \\ Potsdam, New York 13676, U.S.A.
}

(Received September 17, 1977)

\begin{abstract}
It has been shown that the evolution of hydrocyanic acid during the thermal oxidative degradation of aliphatic and aromatic polyurethanes is inhibited by metals such as $\mathrm{Cu}$ and $\mathrm{Co}$ powders, their oxides, and decomposable compounds. Other metals are much less efficient inhibitor. The inhibition efficiency also depends on the degree of dispersion. $\mathrm{Cu}$ or its oxides and decomposable compounds are the most powerful inhibitors; very effective are copper films ( 400 to $1000-\AA$ thick) deposited on polymer films. It is shown that $\mathrm{HCN}$ evolved from $\mathrm{NaCN}$ is catalytically decomposed in an air stream; if the velocity of such a stream is low and the $\mathrm{HCN}$ concentration is small, then the main decomposition product is $\mathbf{N}_{2}$ (ca. $90 \%$ ) plus small amounts of nitrogen oxides, $\mathrm{H}_{2} \mathrm{O}$, and $\mathrm{CO}_{2}$. The catalytic decomposition reaction of $\mathrm{HCN}$ evolved from polyurethanes is exactly analogous to that for $\mathrm{NaCN}$, i.e., at low air flow rates and low HCN concentrations mainly $\mathrm{N}_{2}$ is the decomposition product. The results obtained for $\mathrm{HCN}$ evolved from $\mathrm{NaCN}$ agree well with those of previous workers. It can be definitely concluded that the inhibition by copper of $\mathrm{HCN}$ evolution from polyurethanes and other nitrogen containing polymers is not due to a change in the oxidative degradation mechanism of the polymers but is due to the catalytic decomposition of $\mathrm{HCN}$ evolved from polymers.
\end{abstract}

KEY WORDS Oxidative Degradation / Hydrocyanic Acid / Polyurethenes / Copperoxide Catalysis / Inhibition /

The kinetics and mechanism of the evolution of hydrocyanic acid from aliphatic and aromatic polyurethanes during oxidative degradation have recently been investigated by Jellinek and Takada. ${ }^{1}$ During this work it was found that copper powder and easily decomposable copper compounds dispersed in the polymer films inhibit the evolution of hydrocyanic acid almost completely during the thermal oxidation of the polymers. Other metals and metal compounds are less efficient for this inhibition process. In the present paper the mechanism of this inhibition reaction has been studied. It emerges that $\mathrm{HCN}$, as soon as it is evolved from the polymer, is catalytically oxidized

\footnotetext{
* Paper Presented at 26th International Congress, IUPAC, Tokyo, September 4-10, 1977.

** Present Address: Research Laboratories, American Cyanamide Co., New Jersey, U.S.A.

*** Present Address; Research Center, Sanyo Chemical Industries Ltd., Kyoto, Japan.
}

and decomposed. About fifty years ago this catalytic oxidation of $\mathrm{HCN}$ was investigated by various authors. $^{2-4}$ It is shown here that the mechanisms of inhibition of $\mathrm{HCN}$ evolution from polymers agrees well with the catalytic oxidative decomposition mechanism of HCN. The results obtained by modern methods such as chromatography and measurements by specific ion electrodes are in accordance with results obtained in the past.

\section{EXPERIMENTAL}

\section{Materials}

Polyurethanes were prepared (1) from tetramethylene glycol and diisocyanate in solution according to Marvel and Johnson ${ }^{5}$ (linear aliphatic polyurethane) and (2) from tetramethylene glycol and methylene bis(4-phenylisocyanate) according to Lyman $^{6}$ (linear aromatic polyurethane). The polymers were, after purification, thoroughly dried 
under high vacuum $\left(<10^{-5}\right.$ torr $)$ at $50^{\circ} \mathrm{C}$ for at least $72 \mathrm{hr}$.

\section{APPARATUS AND TECHNIQUES}

The principle of the degradation techniques was as follows. An air stream was passed over the polymer film heated to the desired temperature. This stream was then led into a $1-\mathrm{N} \mathrm{NaOH}$ solution where all of the HCN gas was absorbed and transformed to $\mathrm{NaCN}$. The concentration of $\mathrm{CN}^{-}$ ions was continuously monitored with a specific $\mathrm{CN}^{-}$ion electrode (Orion Inc.). The respective e.m.f. values were reproducible within $\pm 5 \mathrm{mV}$ (depending somewhat on the total $\mathrm{CN}^{-}$ion concentration) or $2 \%$ to $5 \%$. Plotting data $v s$. time averages them and makes them more accurate.

The quartz reaction vessel for this thermal oxidative degradation of polymer films (usually $15 \mu$ thick; at these thicknesses diffusion control by $\mathrm{O}_{2}$ is negligible ${ }^{1}$ ) is shown in Figure 1. It is provided with a gas inlet (A) and outlet (B); its diameter is $6 \mathrm{~cm}$. All joints connecting this vessel to the rest of the apparatus assembly were at least $6 \mathrm{~cm}$ removed from the hot surface of the liquid metal bath $(\mathrm{Pb} / \mathrm{Sn} 1: 1$ by weight $)$ into which the vessel is eventually immersed. The temperature of the thermostated bath was constant to $\pm 0.5^{\circ} \mathrm{C}$. The vessel was completely submerged in the liquid metal bath at time $t=0$; its bottom was touched by the point of a chromel-alumel thermocouple and the temperature indicated was taken as the reaction temperature.

A polymer film was deposited at the bottom of this reaction vessel as follows. Usually a solution of $50 \mathrm{mg}$ to $100 \mathrm{mg}$ of polymer was prepared (in freshly distilled $m$-cresol for the aliphatic polyurethane and in DMF for aromatic polyurethane). This solution was slowly evaporated in the reaction vessel; a film of $15 \mu(50 \mathrm{mg})$ thickness was formed; it was thoroughly dried under high vacuum $\left(10^{-5}\right.$ torr or better) for at least $72 \mathrm{hr}$.

Metal powder was mixed into the polymer solution before evaporation for the inhibition experiments; also easily decomposable metal compounds were used in a number of cases. Some experiments were performed with copper films vacuum deposited on polymer films. These were oxidatively heated in a tube furnace (see Figure 2). The thickness of these copper metal films was between $400 \mathrm{~A}$ to $1000 \mathrm{~A}$.

The metal and corresponding polymer films were

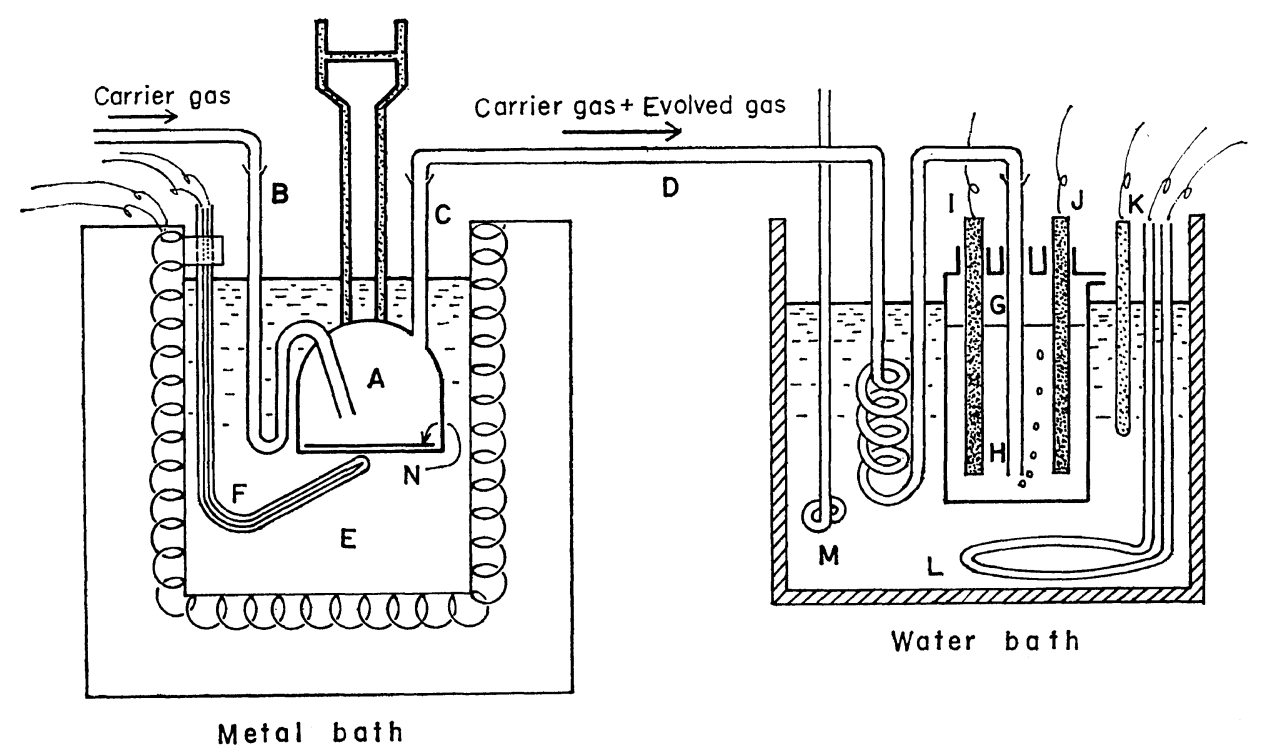

Figure 1. Apparatus assembly for monitoring $\mathrm{HCN}$ evolution: $\mathrm{A}$, reaction vessel; $\mathrm{B}$, inlet of reaction vessel; $C$, outlet of reaction vessel; $D$, connection tube; $E$, metal bath; $F$, thermocouple, $\mathrm{G}$, absorption bottle; $\mathrm{H}$, absorption medium; I, cyanide electrode; $\mathrm{J}$, reference electrode; $\mathrm{K}$, thermistor; L, heater; $M$, stirrer; $N$, polymer film. 


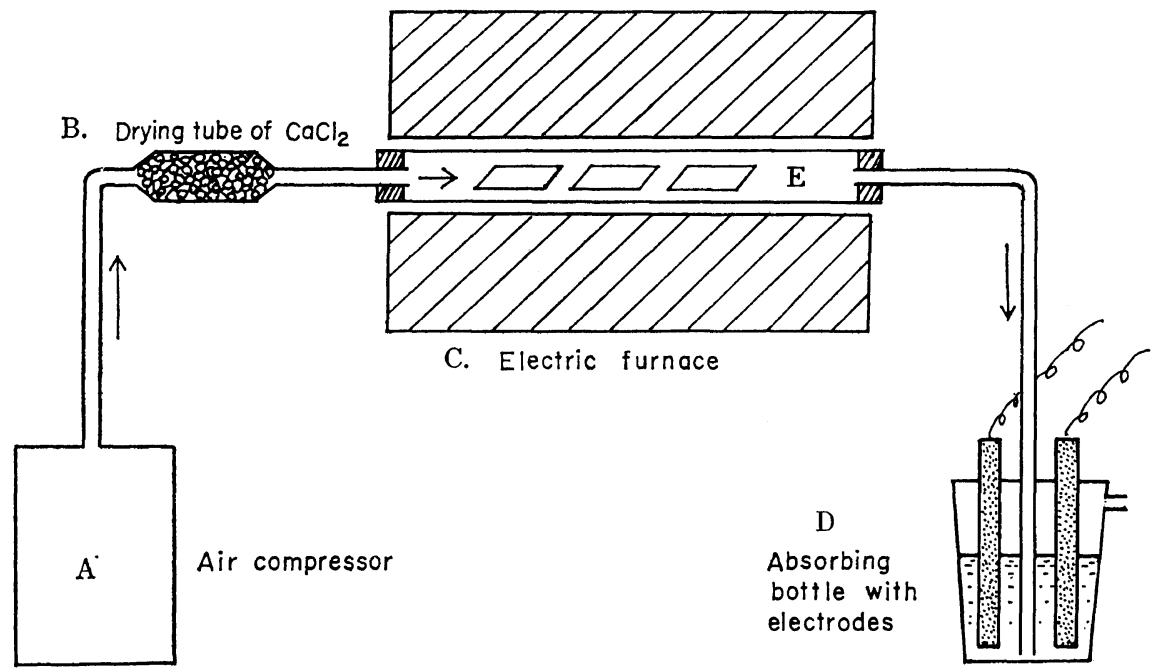

Figure 2. Apparatus assembly for studying the effect of thin copper films on inhibition of $\mathrm{HCN}$ from polyurethanes.

prepared as follows: aliphatic polyurethane was taken for these experiments. A few drops of a $5 \%$ by weight of polymer solution in DMF were placed on a microscope slide $(24 \times 50 \times 2 \mathrm{~mm})$. The solution was spread over the whole surface of the glass plates, which were placed in a desiccator until the solvent had evaporated. Complete drying of the polymer films was achieved under high vacuum ( $c a \cdot 10^{-5}$ torr) at $60^{\circ} \mathrm{C}$ for $24 \mathrm{hr}$. The thickness of the films was between $6 \mu$ to $15 \mu$. Copper films were vacuum deposited onto the polymer films from a Mo-boat (standard Velco V5-9 vacuum station). The deposition was carried out after a pressure of $10^{-6}$ torr was reached. The pressure was kept below $5 \times 10^{-6}$ torr throughout the deposition process. The thickness of the copper deposit was monitored with a quartz crystal oscillator. The films were uniform in thickness within about $3 \%$ (this percentage is based on calculations of the incident flux from a point source).*

Degradation of the metal covered polymer films were carried out in a Lindberg Heavi Duty electric tube furnace (see Figure 2). A pyrex glass tube served as the reaction vessel into which the copperpolymer coated slides were placed. The tempera-

* Our thanks are due to Dr. A. Czanderna, Physics Dept., Clarkson, for having these depositions carried out. ture was $400^{\circ} \mathrm{C}$ and an air stream was passed through the tube during the experiment. The $\mathrm{CN}^{-}$ ion concentration was continuously monitored by a specific $\mathrm{CN}^{-}$ion electrode. The $\mathrm{Cu}$ film remained as a coherent black $\mathrm{CuO}$ film on the polymer substrate during oxidation.

Next, the apparatus and techniques will be described for the evolution of $\mathrm{HCN}$ from $\mathrm{NaCN}$ and polyurethanes, for the catalytic oxidation of $\mathrm{HCN}$, and for the analyses of the product gases.

The first apparatus used for these investigations is shown in Figure 3. $\mathrm{H}_{2} \mathrm{SO}_{4}(1: 1)$ was stored in the side arm of the reaction vessel $\mathrm{C}$. At the start of the experiment, $\mathrm{H}_{2} \mathrm{SO}_{4}$ was pressed over into the reaction vessel where it mixed with highly concentrated aq. $\mathrm{NaCN}$. The evolved $\mathrm{HCN}$ was carried by an air stream through copper powder located in an horizontal tube furnace (Heavi-Duty), which was heated to $300^{\circ} \mathrm{C}$. The $\mathrm{NaCN}-\mathrm{H}_{2} \mathrm{SO}_{4}$ mixture was eventually boiled to expel all dissolved $\mathrm{HCN}$. The air, $\mathrm{HCN}$, and other product gases were bubbled through $1-\mathrm{N} \mathrm{NaOH}$, where all $\mathrm{HCN}$ was absorbed. The concentration of $\mathrm{CN}^{-}$ions was continuously monitored by a specific $\mathrm{CN}^{-}$ion electrode (Orion Inc.). Experiments were carried out at $300^{\circ} \mathrm{C}$.

A slight modification was made to the first apparatus (see Figure 3) for general chromatographic analysis. Two traps (see Figure 4) were connected 


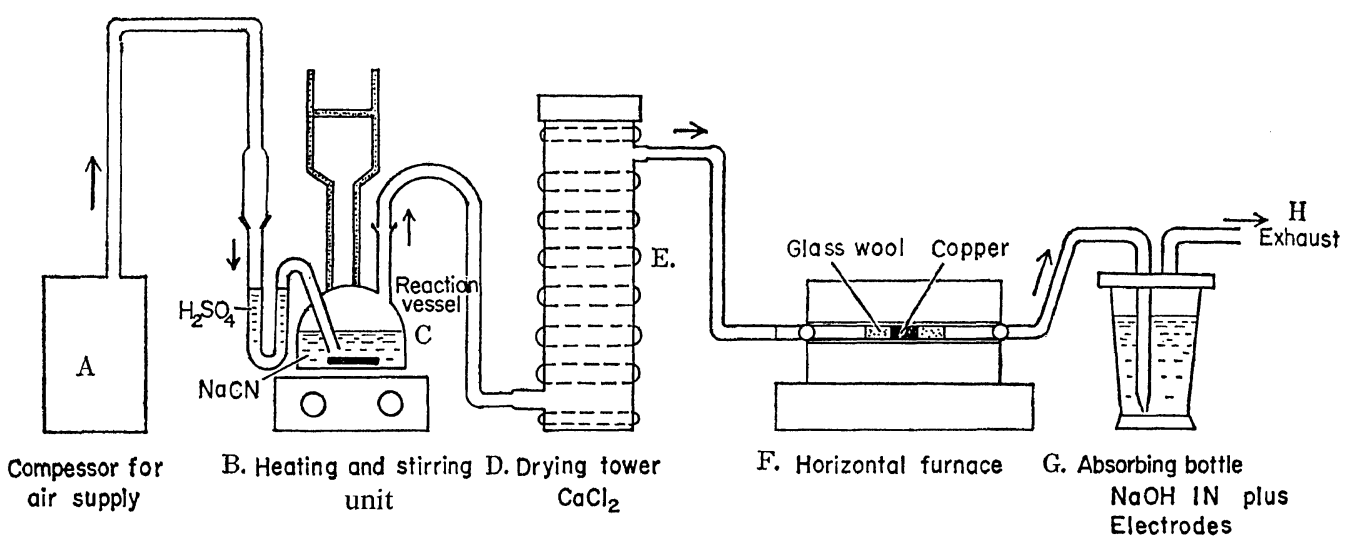

Figure 3. Apparatus assembly for generation of $\mathrm{HCN}$ from $\mathrm{NaCH}-\mathrm{H}_{2} \mathrm{SO}_{4}$ and catalytic oxidation of $\mathrm{HCN}$ by $\mathrm{Cu} / \mathrm{CuO}$ powder at $300^{\circ} \mathrm{C}$ : A, compressor for air supply; B, heating \& stirring unit; $\mathrm{C}$, reaction vessel; $\mathrm{D}$, drying tower of $\mathrm{CaCl}_{2}$; E, heating tape; F, horizontal furnace; $\mathrm{G}$, absorbing bottle, $1-\mathrm{N} \mathrm{NaOH} ; \mathrm{H}$, exhaust.

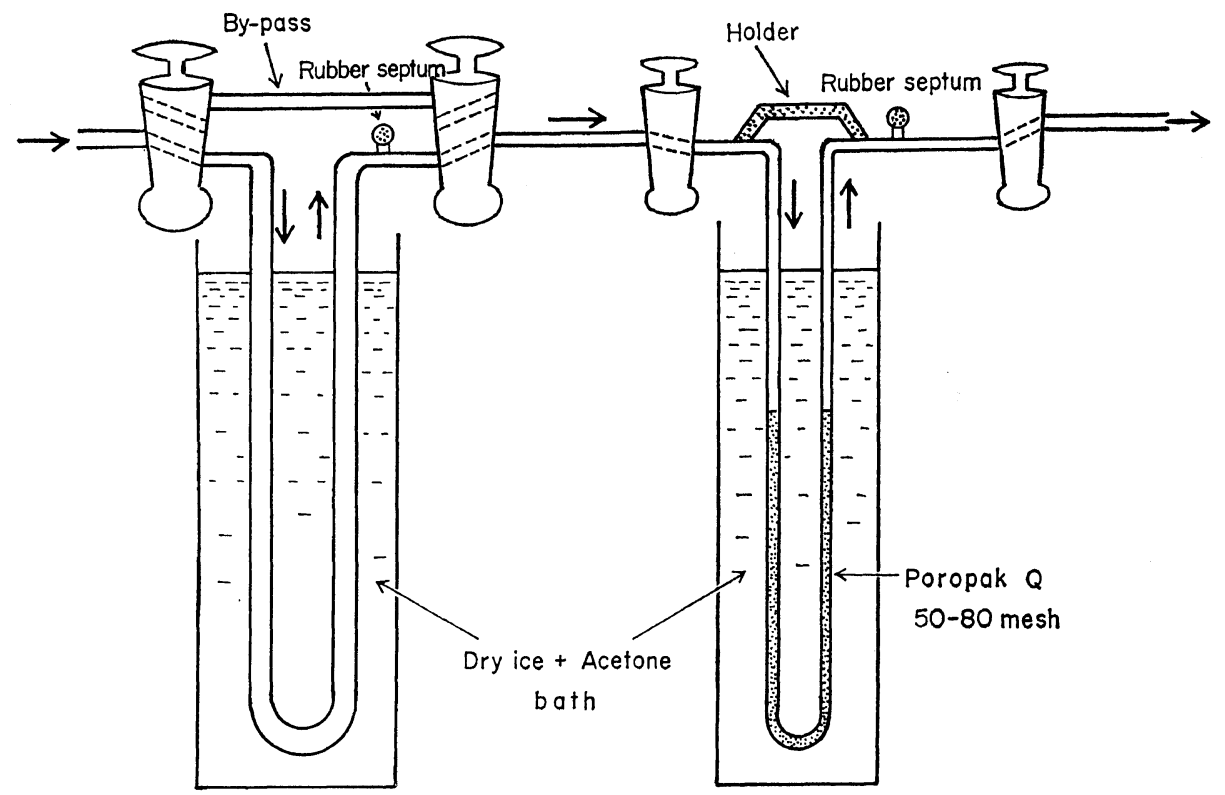

Figure 4. Double-trap for condensing gaseous products from $\mathrm{HCN}$ oxidation.

to it, in which reaction products and also unreacted $\mathrm{HCN}$ were condensed after the catalytic reaction had taken place in the hot copper zone. The first trap was cooled to about $-78^{\circ} \mathrm{C}$ by a dry ice-acetone mixture; the second trap, which contained Poropak Q, was also cooled to $c a$. $-78^{\circ} \mathrm{C}$. The first trap condenses water, while the second one absorbs gases such as $\mathrm{N}_{2}, \mathrm{NO}_{2}$, $\mathrm{CO}, \mathrm{CO}_{2}$, etc. After condensation or absorption of the product gases, the traps were closed and warmed to room temperature. The contents of the first trap were sampled by a gas tight syringe (ca. $500 \mu l$ ) and chromatographed; the carrier gas was $\mathrm{N}_{2}$.

A second apparatus (see Figure 5) was used at $300^{\circ} \mathrm{C}$ for the detection of $\mathrm{N}_{2}$ in the product gases of the catalytically decomposed HCN. A mixture of pure oxygen plus $\mathrm{He}(80: 20$ by volume) was 


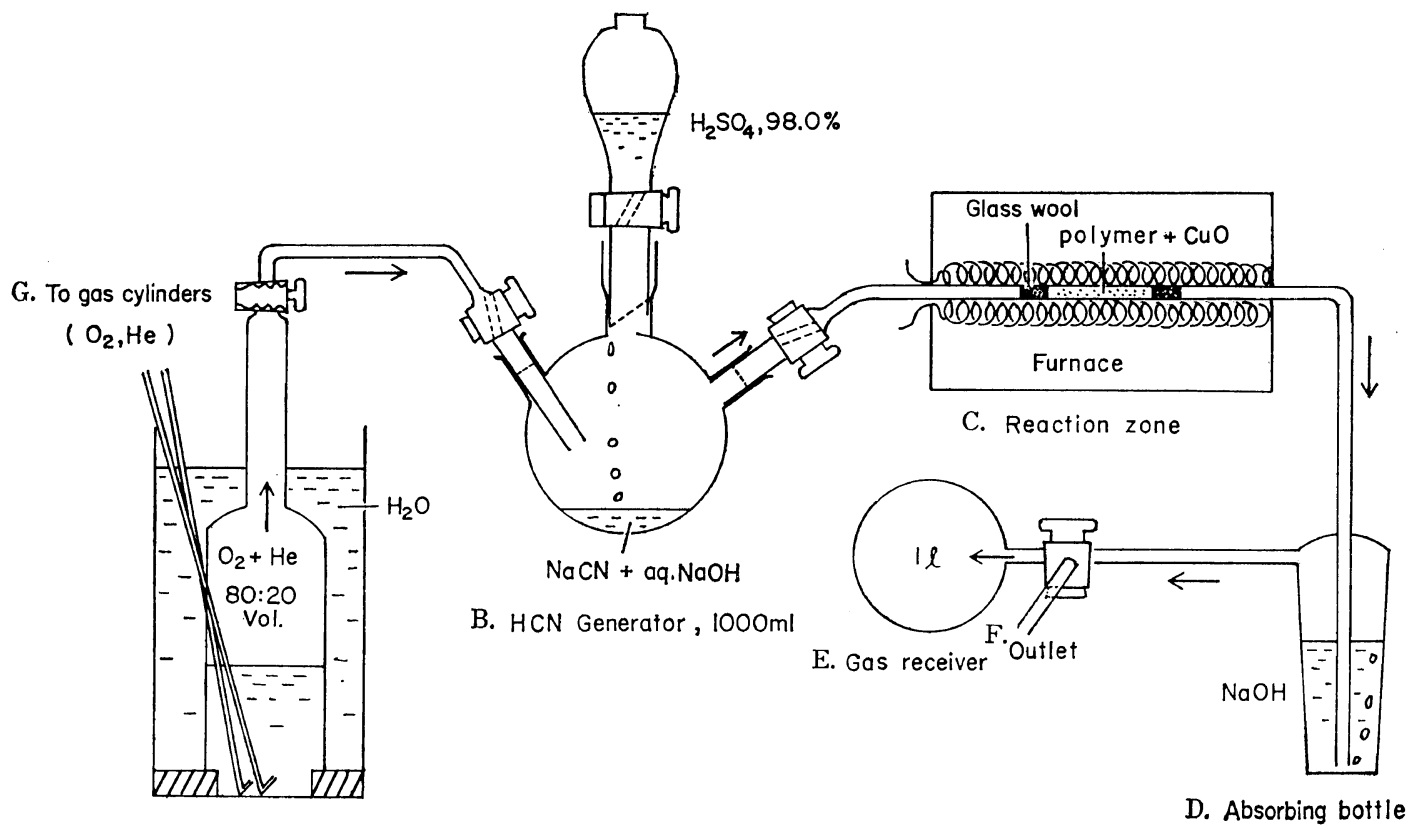

A. Gas container $\left(\mathrm{O}_{2}+\mathrm{He}\right)$

Figure 5. Apparatus assembly for oxidation of $\mathrm{HCN}$ : A, gas container $\left(\mathrm{He}+\mathrm{O}_{2}\right) ; \mathrm{B}, \mathrm{HCN}$ generator; $1000 \mathrm{ml}$; $\mathrm{C}$, reaction zone; $\mathrm{D}$, absorbing bottle; $\mathrm{E}$, gas receiver; $\mathrm{F}$, outlet; $\mathrm{G}$, to gas cylinder $\left(\mathrm{O}_{2}, \mathrm{He}\right)$.

passed through the apparatus. The absence of $\mathrm{N}_{2}$ in the apparatus was proved chromatographically; only traces of $\mathrm{N}_{2}$ could be detected. Usually $1.2 \mathrm{~g}$ to $2.0 \mathrm{~g}$ of $\mathrm{NaCN}$ were dissolved in a few $\mathrm{m} l$ of aq. $\mathrm{NaOH}$ for the catalysis experiments conducted at $300^{\circ} \mathrm{C}$. The furnace tube (pyrex) had a diameter of $0.5 \mathrm{~cm} ; 3 \mathrm{~cm}$ of its length in the middle were filled with $\mathrm{Cu}$-powder $(1 \mathrm{~g}$ of $\mathrm{Cu}$-dust, 325 mesh). Unreacted $\mathrm{HCN}$ was absorbed in $\mathrm{NaOH}(\mathrm{D})$. The $1 l$ gas receiver (Figure 5), which was provided with a three way tap (F), was evacuated. The gas flow was kept constant manually.

The chromatograph for the gas analysis was a Gow-Mac Dual Column (series 550) one with a thermal conductivity detector.

The products obtained in the second apparatus (see Figure 5, E) were sampled with a syringe (ca. $2500 \mu l$ ) and injected into the chromatograph. The carrier gas in this case was $\mathrm{He}$ and oxygen; analysis for $\mathrm{N}_{2}$ only was performed in this case.

All gases were identified by comparing their chromatograms obtained under identical conditions with those of pure gases.

The retention times in seconds were as follows:
$\mathrm{O}_{2}=17.6, \mathrm{CO}=17.7$ (negative peak), $\mathrm{CO}_{2}=38.8$ (negative peak), $\mathrm{NO}_{2}=317.6, \mathrm{H}_{2} \mathrm{O}=341.2$. Column temperature $51^{\circ} \mathrm{C}$, injector temperature $57^{\circ} \mathrm{C}$, detector temperature $87^{\circ} \mathrm{C}$; carrier gas $\mathrm{N}_{2}$ : speed $35.4 \mathrm{ml} / \mathrm{min}$; filament current $110 \mathrm{ma}$; recorder expansion $1 \mathrm{mo}$, recorder speed $1 / 5^{\prime \prime} / \mathrm{min}$. The column was $1 / 8^{\prime \prime} \times 6^{\prime}$ stainless steel, Poropak $Q$ $80 / 100$ mesh.

The following conditions were chosen for the separation of $\mathrm{HCN}$ from air and moisture: column temperature $70^{\circ} \mathrm{C}$, injector temperature $70^{\circ} \mathrm{C}$, detector temperature $90^{\circ} \mathrm{C}$, carrier gas $\mathrm{N}_{2}$, speed $40 \mathrm{~m} / / \mathrm{min}$, filament current $105 \mathrm{ma}$.

As pointed out above, the second apparatus was used for the determination of $\mathrm{N}_{2}$ in the product gases. The conditions were as follows: column temperature $65^{\circ} \mathrm{C}$, carrier gas $\mathrm{He}, 40 \mathrm{~atm}$., at $600 \mathrm{ml} / \mathrm{min}$, recorder speed $1^{\prime \prime} / \mathrm{min}$, column B (molecular sieve 5A).

IR spectra of a solid reaction product in the form of $\mathrm{KBr}$ pellets were measured with a Beckman Spectrophotometer No. 12.

Ozone was produced by passing dry air through an ozonator (03V1 Ozonator, Ozone Research and 


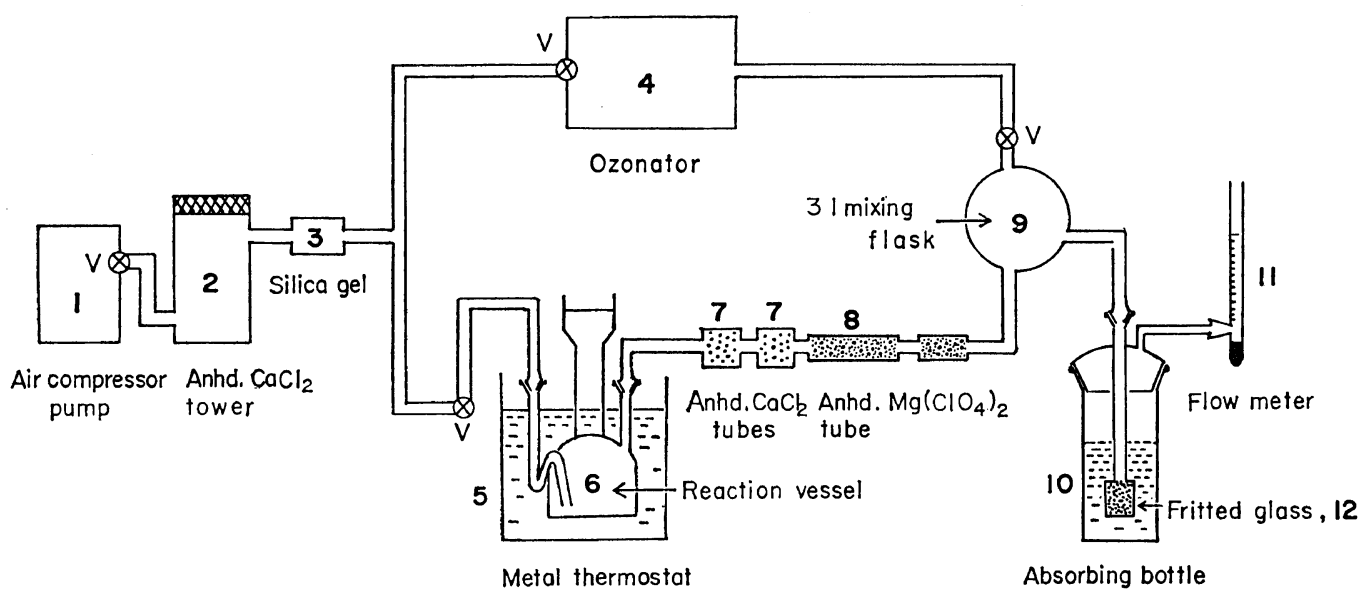

Figure 6. Apparatus assembly for detection of oxides of nitrogen produced by catalytic oxidation of $\mathrm{HCN}$ by copper/copper oxide: 1, air compressor pump; 2, anhyd $\mathrm{CaCl}_{2}$ tower; 3 , silica gel; 4, ozonator; 5, metal thermostat; 6 , reaction vessel; 7, anhyd $\mathrm{CaCl}_{2}$ tubes; 8 , anhyd $\mathrm{Mg}\left(\mathrm{ClO}_{4}\right)_{2}$ tube; $9,3-l$ mixing flask; 10 , absorbing bottle; 11 , flow meter; 12 , fritted glass; $\mathrm{V}$, valves for flow control.

Equipment Co.).

Specific $\mathrm{CN}^{-}$ion and $\mathrm{NO}_{3}{ }^{-}$ion electrodes were obtained from Orion Research Inc.; e.m.f. measurements were made with a Corning $\mathrm{pH}$ meter; the values given by the electrodes were reproducible within $\pm 5 \mathrm{mV}$ or $2 \%$ to $5 \%$ depending on the concentration range.

The apparatus for the analyses of the product gases from polyurethane films is depicted in Figure 6. $\mathrm{NO}$ is determined by oxidation of $\mathrm{NO}_{2}$ by $\mathrm{O}_{3}$ to $\mathrm{N}_{2} \mathrm{O}_{5}$.

\section{EXPERIMENTAL RESULTS}

\section{Inhibition of HCN-Evolution from Polyurethanes}

Figure 7 shows some experimental results for $\mathrm{HCN}$ evolution $\left(281^{\circ} \mathrm{C}\right)$ from aliphatic polyurethane films cast from formic acid and $m$-cresol, respectively, without addition of $\mathrm{Cu}$ or $\mathrm{Cu}$-compounds. An air stream was passed continuously over the polymer films.

The data are plotted as $m_{\mathrm{HCN}} v s$. time, where $m_{\mathrm{HCN}}$ are the moles of $\mathrm{HCN}$ evolved from one unit mole of polymer. The molecular weights for the repeating units for the polyurethanes investigated are: aliphatic about 258 and aromatic about 340. Each unit mole can produce at most 2 mol of $\mathrm{HCN}$, since there are two urethane groups in each repeating unit.

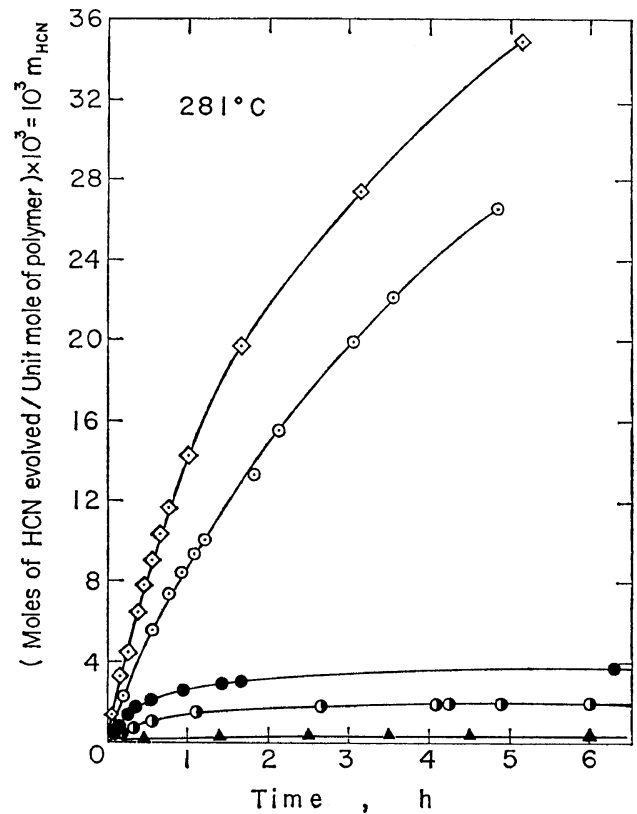

Figure 7. Inhibition of $\mathrm{HCN}$ evolution by $\mathrm{Cu}$-powder $\mathrm{Cu}$-phenolate, and $\mathrm{Cu}$-formate in presence of air, aliphatic polyurethane, $281^{\circ} \mathrm{C}$ : $\diamond$, polymer film $(60 \mathrm{mg})$ made from formic acid; $O$, polymer film $(70 \mathrm{mg})$ made from $m$-cresol; $\bullet$, polymer film $(60 \mathrm{mg})$ from $m$-cresol $+10 \% \mathrm{Cu}$-phenolate; $\quad \mathrm{O}$, polymer film (70 mg) from formic acid $+15 \%$ Cu-formate; $\Delta$, polymer film $(70 \mathrm{mg})$ from formic acid $+50 \mathrm{mg}$ copper dust. 
If one mole of the repeating unit is considered as representing $100 \%$ of the weight, then the weight percentage of $\mathrm{HCN}$ evolved from one unit mole of polymer is given by

$$
\% \mathrm{w} / \mathrm{w} \text { of } \mathrm{HCN}=\frac{m_{\mathrm{HCN}} M W_{\mathrm{HCN}} \times 100}{M W_{\text {repeat unit }}} \% \mathrm{w} / \mathrm{w}
$$

MW stands for molecular weight. The maximum amounts of $\mathrm{HCN}$ in \% weight which can be evolved from one unit mole are $20.93 \% \mathrm{w} / \mathrm{w}$ and $15.88 \%$ $\mathrm{w} / \mathrm{w}$ for the aliphatic and aromatic polyurethane, respectively.

Figure 7 shows also the results of experiments $\left(281^{\circ} \mathrm{C}\right)$ with the addition of Cu-phenolate, $\mathrm{Cu}$ formate and copper dust, respectively. These and the subsequent experiments were carried out in the apparatus shown in Figure 1. Figures 8 and 9 give results obtained at $300^{\circ} \mathrm{C}$ and $400^{\circ} \mathrm{C} . \mathrm{Cu}$ and $\mathrm{Co}$ and their compounds are very efficient

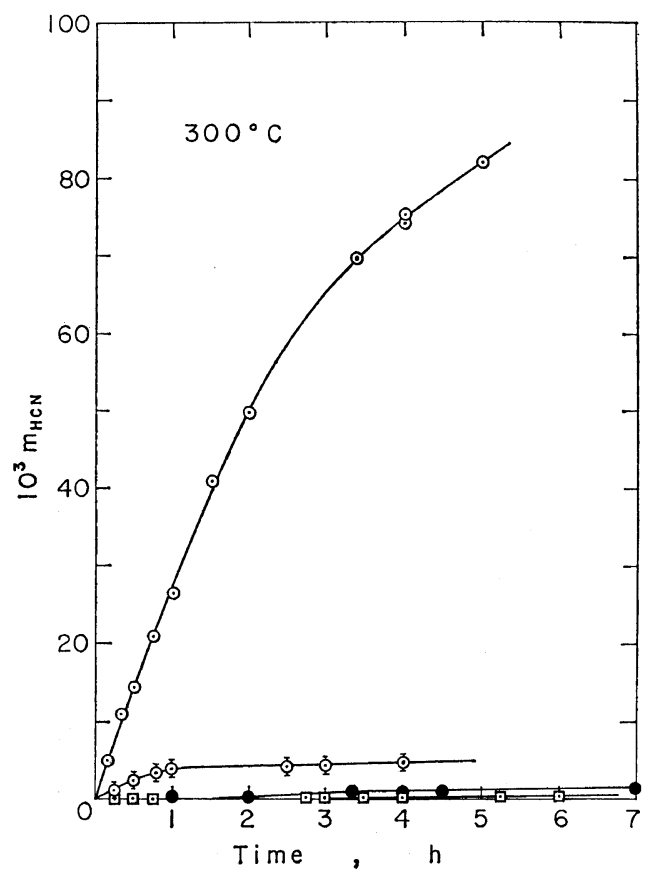

Figure 8. Hydrogen cyanide evolution from aliphatic polyurethane, degradation in air at $300^{\circ} \mathrm{C}$ in the presence or absence of copper, copper formate, and cobalt formate: $O, 70-\mathrm{mg}$ polymer; $O, 70-\mathrm{mg}$ polymer +7-mg copper formate; $\bullet$, 70-mg polymer + 7-mg cobalt formate; $\square, 70-\mathrm{mg}$ polymer+about $50-\mathrm{mg}$ copper metal dust. inhibitors. The efficiency, in part, also depends on the degree of dispersion of the inhibitor in the polymer film. Experiments showed that coarse copper powder is less efficient than fine powder for to equal weights. Compounds after decomposition in the polymer film have the metal in a very fine dispersed state. The polymer in this case is aliphatic polyurethane.

Figure 10 shows the effect of copper and some of its compounds for the case of the aromatic polyurethane $\left(400^{\circ} \mathrm{C}\right)$. The results are similar to those for the aliphatic polymer. These experiments were carried out in the apparatus depicted in Figure 1. Figure 11 gives results for various Co compound inhibitors $\left(400^{\circ} \mathrm{C}\right)$. These experiments were performed with the aromatic polymer (apparatus, see Figure 1). Figure 12 gives the effect of various metal salts and oxides on $\mathrm{HCN}$ evolution from aromatic polyurethane $\left(400^{\circ} \mathrm{C}\right)$. It

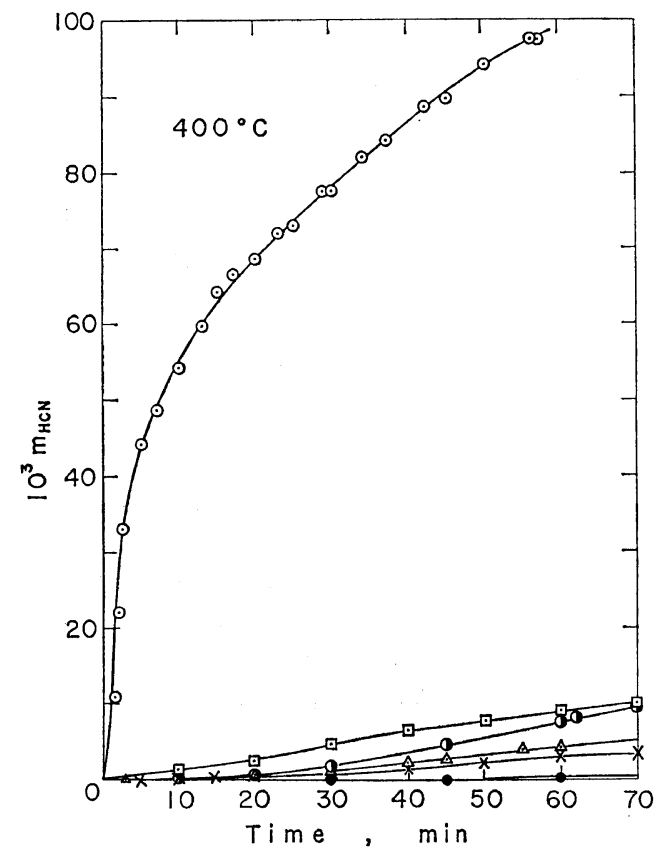

Figure 9. Hydrogen cyanide evolution from aliphatic polyurethane; degradation in air at $400^{\circ} \mathrm{C}$ in the presence or absence of varying amounts of cobalt oxide, cobalt formate, and copper formate: $0,70-\mathrm{mg}$ polymer; $\square, 70$-mg polymer +15-mg copper formate; o, 70-mg polymer +12.6-mg cobalt formate; $\triangle$, 70-mg polymer $+15-\mathrm{mg}$ cobalt formate; $\times, 70-\mathrm{mg}$ polymer + $20 \mathrm{mg}$ cobalt formate; $\bigcirc 70-\mathrm{mg}$ polymer $+50-\mathrm{mg}$ cobalt oxide. 


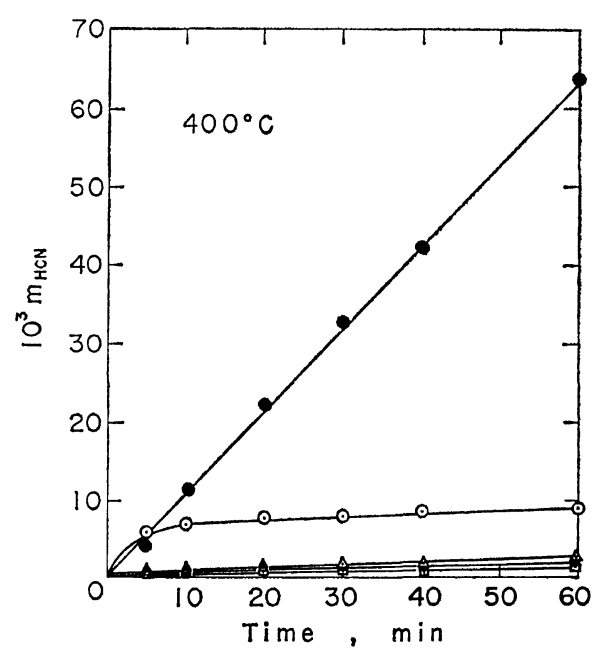

Figure 10. Effect of copper compounds on inhibition of $\mathrm{HCN}$ evolution from aromatic polyurethane $\left(400^{\circ} \mathrm{C}\right.$, air);, blank; O, 30- \% copper dust; $\Delta, 100-\%$ copper dust; $\triangle, 10-\%$ copper acetate; $\square, 10-\%$ copper formate; $\triangle, 10-\%$ copper phenolate.

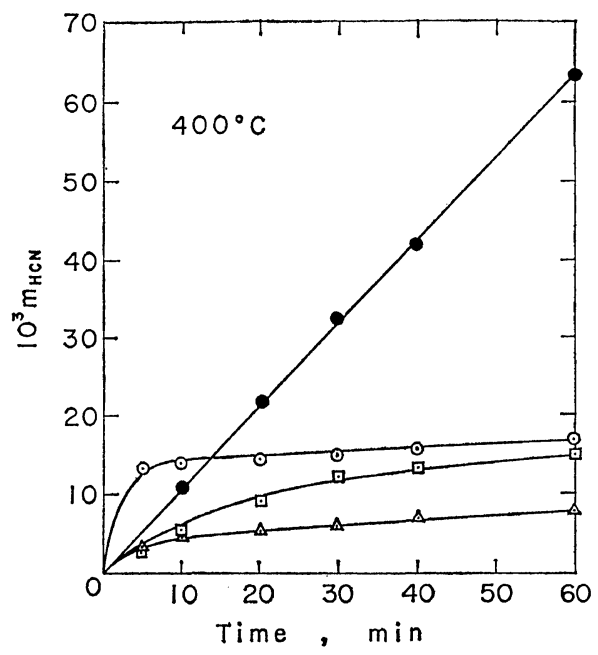

Figure 11. Effect of cobalt compounds on inhibition of $\mathrm{HCN}$ evolution from aromatic polyurethane $\left(400^{\circ} \mathrm{C}\right.$, air): $\bullet$, blank; $O, 10-\%$ cobalt acetate; $\square, 10-\%$ cobalt oxide; $\triangle, 10-\%$ cobalt formate.

emerges from all these results that $\mathrm{Cu}$-dust is the most effective inhibitor.

Figure 13 shows results for aliphatic polymer films covered with thin Cu-films. The weight percentages relate to the amount of copper on the polymer film (weight $100 \%$ ). The $10-\% \mathrm{Cu}-$ film is quite an efficient inhibitor. The $\mathrm{Cu}-$ film

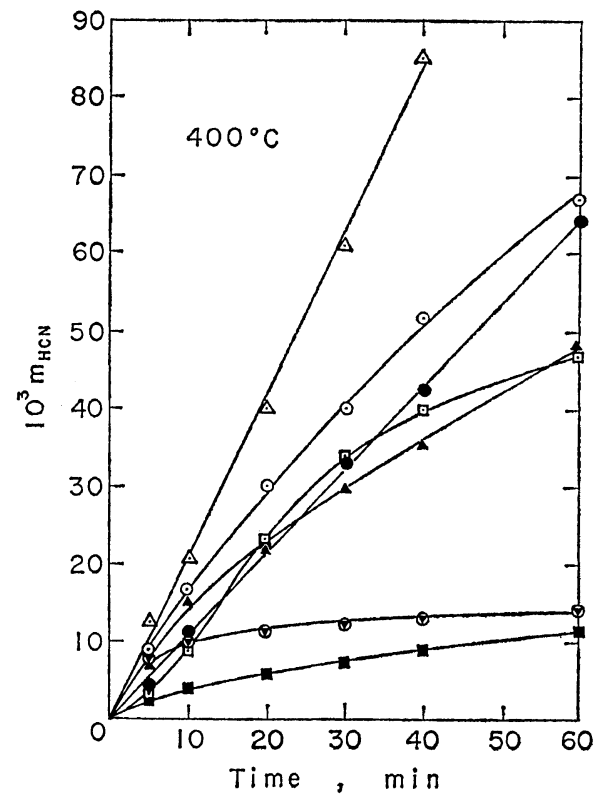

Figure 12. Effect of various metal compounds on inhibition of $\mathrm{HCN}$ evolution from aromatic polyurethane $\left(400^{\circ} \mathrm{C}\right.$, air): ๑, blank; $\mathrm{O}, 10-\%$ nickel formate; $\boldsymbol{\square}, 10-\%$ nickel acetate; $\square, 10-\%$ lead oxide; $\Delta, 10-\%$ magnesium oxide; $O, 10-\%$ chromium oxide; $\triangle, 10-\%$ ferric oxide.

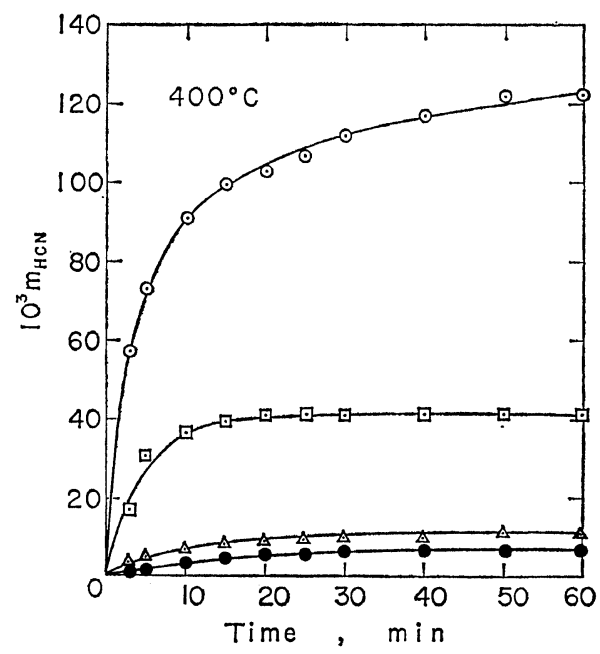

Figure 13. Effect of thin copper films on inhibition of $\mathrm{HCN}$ from polyurethane: $\bigcirc$, blank; $\square, 2.6 \%$ of copper film; $\triangle, 4.7 \%$ of copper film; $\bullet, 10.3 \%$ of copper film.

is completely oxidized to black $\mathrm{CuO}$ during degradation but remains behind as a coherent film. 
Table I. Relative effectivenesses of thin films of $\mathrm{Cu}, \mathrm{Cu}$-dust, and $\mathrm{Cu}$-formate for the inhibition of $\mathrm{HCN}$ evolution from aliphatic polyurethane

\begin{tabular}{|c|c|c|c|}
\hline $\begin{array}{l}\text { Copper film } \\
\text { or compounds } \\
\text { Cu as \% of } \\
\text { polymer }\end{array}$ & $\begin{array}{l}\text { Evolution } \\
\text { of } \mathrm{HCN} \text {, } \\
\%\end{array}$ & $\underset{{ }^{\circ} \mathrm{C}}{\mathrm{Temp}}$ & $\begin{array}{c}\text { Remarks } \\
\text { (thickness) }\end{array}$ \\
\hline Blank & 100 & 400 & \\
\hline 2.6 & 34 & 400 & $\begin{array}{l}\mathrm{Cu}, \text { about } 431 \mathrm{~A} ; \\
\text { polymer, about } 15 \mu\end{array}$ \\
\hline 4.7 & 9 & 400 & $\begin{array}{l}\mathrm{Cu}, \text { about } 1000 \mathrm{~A} ; \\
\text { polymer, about } 19 \mu\end{array}$ \\
\hline 10.3 & 5 & & \\
\hline \multicolumn{4}{|c|}{ Copper formate, } \\
\hline 20 & 10 & 400 & \\
\hline 10 & 13 & 300 & \\
\hline \multicolumn{4}{|l|}{ Copper dust, } \\
\hline 10 & 23 & 261 & \\
\hline
\end{tabular}

Relative effectivenesses of thin films of $\mathrm{Cu}, \mathrm{Cu}$ dust, and $\mathrm{Cu}$-formate are given in Table $\mathrm{I}$. $\mathrm{Cu}$ formate can be more evenly dispersed in the polymer film than $\mathrm{Cu}$-dust.

\section{Catalytic Oxidation of HCN Evolved from $\mathrm{NaCN}$} HCN Evolution and Carrier Flow Velocity. HCN was evolved as described above by the reaction of $\mathrm{H}_{2} \mathrm{SO}_{4}$ with $\mathrm{NaCN}$ solution (apparatus, see Figure 3). The amount of $\mathrm{HCN}$ absorbed in the $\mathrm{NaOH}$ solution in the absence of $\mathrm{Cu}$-powder was always $85 \%$ to $95 \%$ of the theoretical amount for experiments carried out at $300^{\circ} \mathrm{C}$. At these temperatures $\mathrm{HCN}$ is not oxidized at all. The reason for the somewhat smaller than theoretical amount of HCN obtained is probably due to some adsorption of $\mathrm{HCN}$ in the drying chamber and some remaining in the reaction mixture.

Experiments carried out in the presence of copper or its oxides showed conclusively that HCN is catalytically oxidized. This is demonstrated below.

If the flow rate is high, i.e., if the contact time between $\mathrm{HCN}$ and the catalyst is rather short, then the amount of $\mathrm{HCN}$ absorbed in the $1-N \mathrm{NaOH}$ solution is relatively large.

Some of the results obtained are given in Table II below.

Solid Oxidation Product. A solid white product in very small amounts ( $c a .1 \%$ by weight) is formed when the air flow velocity is high. However, when these velocities are small, all HCN is catalytically decomposed and it can no longer be detected with the $\mathrm{CN}^{-}$ion electrode $(1 \%$ of the theoretical amount can easily be detected, i.e., $2 \mathrm{mg}$ of $\mathrm{HCN}$ evolved from $0.35 \mathrm{~g}$ of $\mathrm{NaCN}$ ). At the same time,

Table II. $\mathrm{HCN}$ gas carried by air through a $300^{\circ} \mathrm{C}$ zone

(a) In absence of copper powder

\begin{tabular}{ccccl}
\hline $\begin{array}{c}\mathrm{NaCN}, \\
\mathrm{g}\end{array}$ & $\begin{array}{c}1: 1 \mathrm{H}_{2} \mathrm{SO}_{4}, \\
\mathrm{ml}\end{array}$ & $\begin{array}{c}\text { Velocity of } \\
\text { air flow }\end{array}$ & $\begin{array}{c}\text { Yield } \\
\text { of } \mathrm{HCN}, \%\end{array}$ & \multicolumn{1}{c}{ Remarks } \\
\hline 0.49 & 1.0 & medium & 96 & $\mathrm{HCN}$ not dried, and not passed through furnace. \\
0.35 & 1.0 & medium & 90 & HCN dried, passed through furnace. \\
0.35 & 1.0 & medium & 84 & $\begin{array}{l}\text { HCN dried, passed through furnace containing } \\
\text { glass wool in tube. }\end{array}$ \\
\hline
\end{tabular}

(b) In presence of copper powder

\begin{tabular}{|c|c|c|c|c|}
\hline $\begin{array}{l}\mathrm{NaNC} \\
\mathrm{g}\end{array}$ & 1: $\underset{\mathrm{m} l}{1} \mathrm{H}_{2} \mathrm{SO}_{4}$ & $\begin{array}{l}\text { Velocity of } \\
\text { air flow }\end{array}$ & $\begin{array}{l}\text { Yield } \\
\text { of } \mathrm{HCN}, \%\end{array}$ & Remarks \\
\hline 0.35 & 0.9 & medium & 1.3 & $\begin{array}{l}\text { HCN was not dried; small amount of white } \\
\text { powder at exit of tube. }\end{array}$ \\
\hline 0.35 & 1.0 & high & 20 & $\begin{array}{l}\text { HCN dried; some yellowish crystalline material } \\
\text { formed at exit of tube. }\end{array}$ \\
\hline 0.35 & 1.0 & medium & 4 & HCN dried; small white crystals at exit of tube. \\
\hline 0.35 & 1.0 & $\begin{array}{l}\text { low } \\
\text { (ca. } 80-90 \text { air } \\
\text { bubbles per minute) }\end{array}$ & e) & HCN dried; no crystalline products. \\
\hline 0.35 & 1.0 & $\begin{array}{l}\text { high } \\
\text { (ca. } 600-900 \text { air } \\
\text { bubbles per minute) }\end{array}$ & 15 & $\begin{array}{l}\text { HCN dried; appreciable amount of white crystal- } \\
\text { line product. }\end{array}$ \\
\hline
\end{tabular}


the solid product is no longer formed. This seems to indicate that this solid product is due to insufficient oxidation of HCN. In any case, the solid is always a negligible fraction of the total amount of HCN.

Attempts were made to identify this white product. In all probability it consists of a mixture of two or more compounds. This is substantiated by the following observations:

(1) The solid product is usually white but sometimes it is slightly yellowish in color.

(2) It does not have a sharp melting point, but only a melting range $\left(97^{\circ} \mathrm{C}\right.$ to $\left.115^{\circ} \mathrm{C}\right)$.

(3) The product is soluble in $\mathrm{NaOH}$ and partly soluble in water, ethanol, and acetone; it is insoluble in toluene and dioxane.

(4) Its IR spectrum ( $\mathrm{KBr}$ pellets) shows the bands given in Table III (all within \pm 10 $\mathrm{cm}^{-1}$ ); cyanuric acid is probably one of the compounds in the solid mixture: its IR spectrum was published by Newman and Badger. $^{7} \quad$ Table III shows the spectral characteristics of this solid product.

The IR spectrum does not fit the characteristics of any simple compound. The product is pro-

Table III. IR spectrum of solid product

\begin{tabular}{|c|c|c|}
\hline $\begin{array}{l}\text { Wave } \\
\text { number, } \\
\mathrm{cm}^{-1}\end{array}$ & $\begin{array}{l}\text { Wave- } \\
\text { lengths, } \\
\mu\end{array}$ & Remarks \\
\hline 3440 & 2.9 & $\begin{array}{l}\text { Very strong; degenerate } \mathrm{N}-\mathrm{H} \\
\text { stretch }\end{array}$ \\
\hline 3340 & 3.0 & $\begin{array}{l}\text { Very strong; degenerate } \mathrm{N}-\mathrm{H} \\
\text { stretch }\end{array}$ \\
\hline 2170 & $4.60 / 4.63$ & $\begin{array}{l}\text { Very weak; (Absence of strong } \\
\text { bands between } 2700 \mathrm{~cm}^{-1} \text { and } \\
1850 \mathrm{~cm}^{-1} \text { proves absence of } \\
\text { of }-\mathrm{C} \equiv \mathrm{N} \text { groups) }\end{array}$ \\
\hline $1692 / 1685$ & 5.9 & $\begin{array}{l}\text { Very strong; degenerate } \mathrm{C}=\mathrm{O} \\
\text { stretch }\end{array}$ \\
\hline $1630 / 1610$ & $6.2 / 6.12$ & Very strong \\
\hline 1463 & 6.82 & $\begin{array}{l}\text { Strong; degenerate in plane ring } \\
\text { stretch }\end{array}$ \\
\hline 1400 & 7.13 & $\begin{array}{l}\text { Medium; degenerate } \mathrm{N}-\mathrm{H} \text { in } \\
\text { plane bend }\end{array}$ \\
\hline 1330 & 7.5 & Medium \\
\hline 1195 & 8.33 & Weak \\
\hline 1157 & 8.6 & Medium \\
\hline 1070 & & $\begin{array}{l}\text { Very weak; degenerate in plane } \\
\text { ring stretch }\end{array}$ \\
\hline 760 & 13.15 & Weak \\
\hline 705 & & Very weak \\
\hline $560 / 530$ & $17.9 / 18.8$ & $\begin{array}{l}\text { Medium; degenerate } \mathrm{C}=\mathrm{O} \text { in } \\
\text { plane bend }\end{array}$ \\
\hline
\end{tabular}

bably a mixture of compounds such as cyanuric acid and cyamelide,<smiles>O=c1[nH]c(=O)[nH]c(=O)[nH]1</smiles>

$\mathrm{HCN}$ seems to be converted to HNCO during oxidation catalyzed by $\mathrm{Cu}$ or $\mathrm{CuO}$; $\mathrm{HNCO}$ poly-

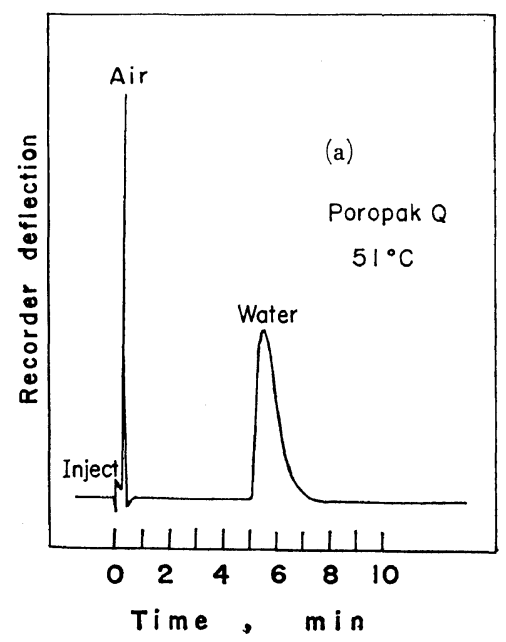

Figure 14 (a). Typical chromatogram of gas (i.e., water) condensed in first trap.

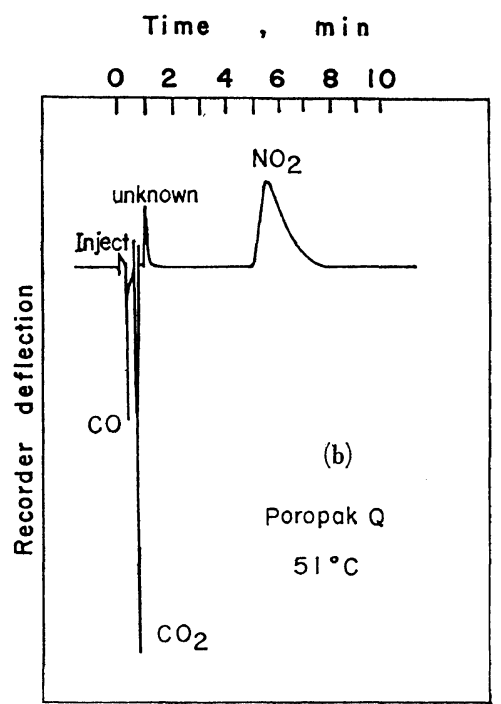

Figure 14 (b). Typical chromatogram of gaseous products absorbed in the second trap. 
merizes quite rapidly. If the contact time with copper is long enough, $\mathrm{HNCO}$, instead of being partially polymerized, is quickly oxidized further to $\mathrm{N}_{2}$, its oxides, and water.

\section{Product Gases from the Catalytic Oxidation of $\mathrm{HCN}$}

Chromatographic Determination of $\mathrm{CO}, \mathrm{CO}_{2}$, and $\mathrm{NO}_{2}$. The apparatus used for these experiments is shown in Figure 4. A typical chromatogram of the content of the first trap obtained by oxidation at $300^{\circ} \mathrm{C}$ is given in Figure 14a. This was identified as water. The gas mixture in the second trap was also chromatographed (see Figure 14b) and was identified as a mixture of $\mathrm{CO}, \mathrm{CO}_{2}$, and $\mathrm{NO}_{2}$, plus one unknown peak, probably $\mathrm{SO}_{2}$, originating from $\mathrm{H}_{2} \mathrm{SO}_{4}$.

The peaks of the chromatograms were identified through their retention times by chromatographing pure gases.

Chromatographic Determination of $\mathrm{N}_{2}$. These experiments were carried out in the apparatus depicted in Figure 6. A mixture of $\mathrm{He}$ and $\mathrm{O}_{2}$ (20: 80 by volume) was the carrier gas. After sweeping the apparatus out with this carrier gas, the absence of $\mathrm{N}_{2}$ in the apparatus was checked by chromatography. Only trace amounts of $\mathrm{N}_{2}$ were left in the apparatus (see Figure 15). This figure also shows that $\mathrm{N}_{2}$ is produced during catalytic oxidation.

Two sets of experiments were performed at dif-

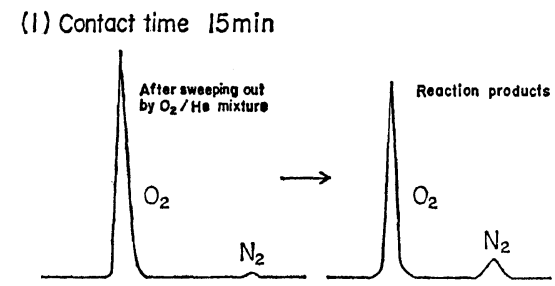

(2) Confact time $75 \mathrm{~min}$

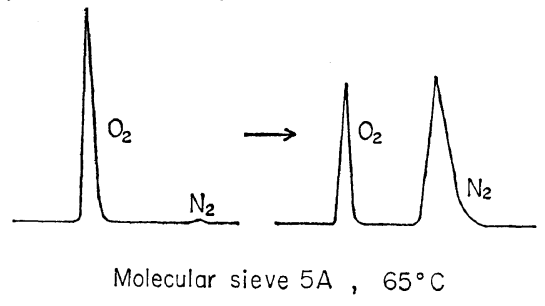

Figure 15. Gas-chromatogram of reaction products of catalytically $(\mathrm{Cu})$ oxydized $\mathrm{HCN}$ gas: (1) $15 \mathrm{~min}$, (2) $75 \mathrm{~min} ; 300^{\circ} \mathrm{C}$. ferent carrier gas flow times, i.e., different contact times of $\mathrm{HCN}$ with $\mathrm{Cu}$ (i.e., $\mathrm{CuO}$ ). These reaction times were $15 \mathrm{~min}$ and $75 \mathrm{~min}$ at $300^{\circ} \mathrm{C}$. The experimental results are summarized in Table IV. As expected, the longer the reaction time, the greater is the conversion of $\mathrm{HCN}$ into $\mathrm{N}_{2}$.

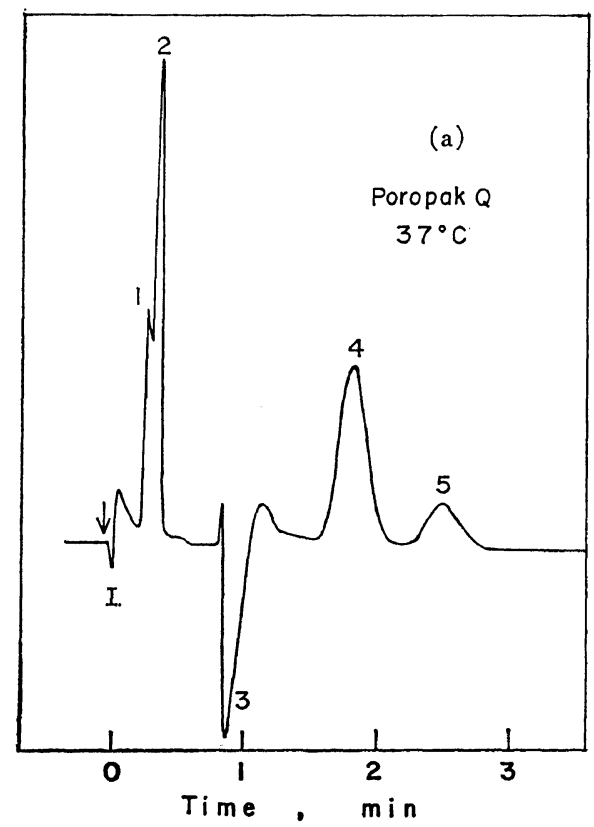

Figure 16 (a). A typical chromatogram of volatile degradation products of polyurethane as separated by Poropak $\mathrm{Q}$ at $37^{\circ} \mathrm{C}$ : 1, hydrogen; 2, oxygen (air); 3 , carbon dioxide; 4 , ethylene; 5 , unidentified (may be propylene).

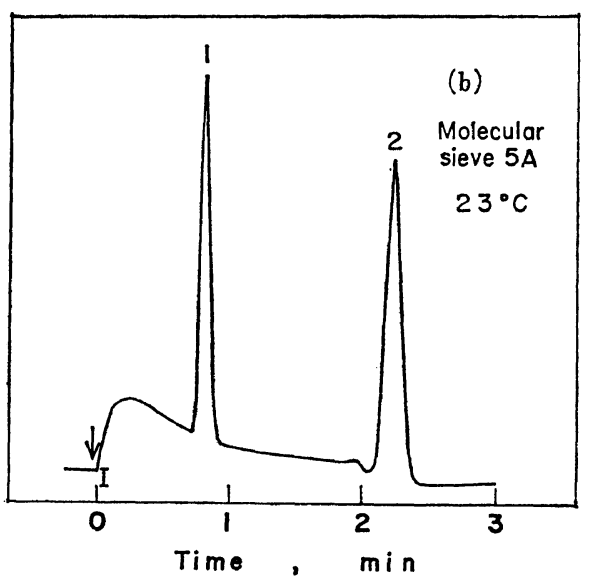

Figure 16 (b). Chromatogram of volatile degradation products as separated by Molecular Sieve 5A Column at $23^{\circ} \mathrm{C}$ : 1 , hydrogen; 2 , oxygen. 
Table IV. Chromatographic $\mathrm{N}_{2}$ determination from catalytically $(\mathrm{Cu})$ oxidized $\mathrm{HCN}$ evolved from $\mathrm{NaCN}\left(300^{\circ} \mathrm{C}\right)$; carrier gas, $\mathrm{He}+\mathrm{O}_{2}$

\begin{tabular}{lcc}
\hline Amount of $\mathrm{NaCN}$ & $1.8 \mathrm{~g}$ & $1.5 \mathrm{~g}$ \\
Reaction time, min & 15 & 15 \\
Conversion to $\mathrm{N}_{2}$ & $8 \%$ & $90 \%$ \\
Remaining $\mathrm{HCN}$ & $30 \% \%^{\mathrm{a}}$ & $8 \% \mathrm{o}$ \\
Other Products $^{\mathrm{b}}$ & $42 \%$ & $2 \%$ \\
${\text { Decrease in } \mathrm{O}_{2}}^{\mathrm{a}}$ & $26 \%$ & $55 \%$ \\
\hline
\end{tabular}

a Percentage of maximal evolved $\mathrm{HCN}$ from $\mathrm{NaCN}$.

b Polymerized products of $\mathrm{HCN}, \mathrm{NO}, \mathrm{NO}_{2}$, etc.

$\mathrm{N}_{2}$ is practically the only product under the conditions of the experiments, i.e., if the flow rate is low or the reaction time is long.

\section{Catalytic Oxidation of HCN Evolved from Poly- urethanes \\ Product Gases from Aliphatic Polyurethane in} the Absence of a Catalyst. These experiments were carried out at $300^{\circ} \mathrm{C}$. Polymer films were prepared as described before. A steady air flow was passed through the apparatus (see Figure 7). The air was dried by anhydrous $\mathrm{CaCl}_{2}$ and silica gel and then passed through the reaction vessel $\left(300^{\circ} \mathrm{C}\right)$. The volatile reaction products were dried by passing them through two tubes filled with anhydrous $\mathrm{CaCl}_{2}$, followed by a tube with anhydrous $\mathrm{MgClO}_{4}$. The gases were then condensed in a trap containing Poropak Q (50-80 mesh) cooled to $-78^{\circ} \mathrm{C}$; a second trap with either Molecular Sieve 5A (3060 mesh) or silica gel ( $40-140$ mesh) cooled to the same temperature was used as a precaution for trapping all volatiles which might have escaped from the first trap (these traps are not shown in this figure; they are depicted in Figure 5). As an additional precaution, the air stream is passed finally through a $1-N \mathrm{NaOH}$ solution to make sure all HCN gas has been removed. This solution did not show any signs of $\mathrm{CN}^{-}$ions. After a definite degradation time, the traps were closed (outlets were also closed by septums) and heated to $90^{\circ} \mathrm{C}$ to $120^{\circ} \mathrm{C}$ unit all volatiles were desorbed. Definite volumes were then withdrawn and chromatographed.

200 to $300 \mathrm{mg}$ films of aliphatic polyurethane were degraded in this case. The analysis was done using either Poropak $\mathrm{Q}$ or Molecular Sieve 5A columns. It is very important to remove moisture from the product gases before condensation in

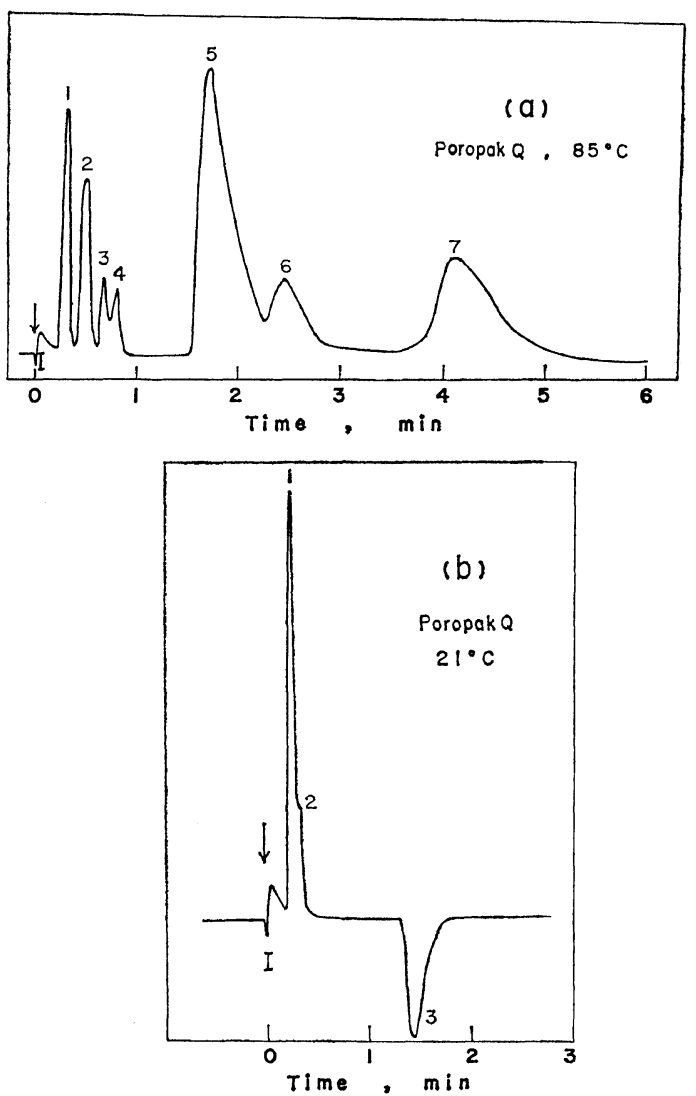

Figure 17 (a). A typical chromatogram of volatile degradation products as separated by Poropak $Q$ column at $85^{\circ} \mathrm{C}$ : 1 oxygen (air); 2, carbondioxide. 3 , ethylene; 4 , unidentified (may be propylene); 5 , water; 6 , hydrogen cyanide; 7 , unidentified (probably an amine).

Figure 17 (b). Chromatogram of volatile products when polyurethane is degraded in presence of copper/ copper oxide; separation by Poropak $\mathrm{Q}$ column at $21^{\circ} \mathrm{C}$ : 1 , oxygen (air); 2 , nitric oxide; 3 , carbon dioxide.

order to successfully detect the presence of $\mathrm{HCN}$, as the latter is highly soluble in water. The response characteristics of the detector are rather low towards $\mathrm{HCN}$.

The following gases were found in the volatile products (results were obtained by experiments where product gases were dried and not dried): (1), oxygen (from carrier air); (2), carbon dioxide; (3), ethylene; (4), unidentified (probably propylene) (5), water; (6), hydrogen cyanide; (7), unidentified (probably an amine); (8), hydrogen. 

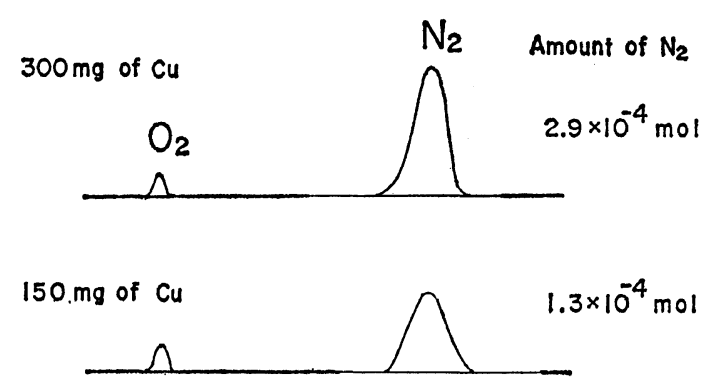

No $\mathrm{Cu}$

$0.26 \times 10^{-4} \mathrm{~mol}$

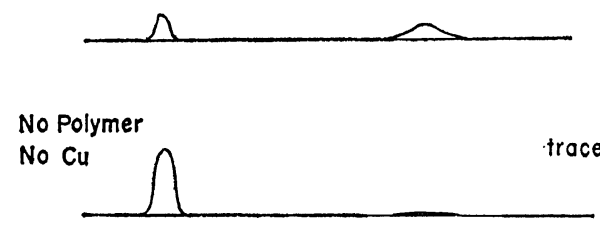

Molecular sieve $5 \mathrm{~A}, 23^{\circ} \mathrm{C}$

Figure 18. Gas-chromatogram of reaction products $\mathrm{N}_{2}$ from polyurethane degradation in the presence of copper dust $\left(3 \mathrm{hr}\right.$ degradation under $30 \mathrm{mmHg}$ of $\mathrm{O}_{2}$, $300^{\circ} \mathrm{C} ; 300 \mathrm{mg}$ of aliphatic polyurethane).

Figure 16a shows some of the products separated by Poropak Q $\left(37^{\circ} \mathrm{C}\right)$. The presence of $\mathrm{H}_{2}$, which is only partially separated by Poropak $\mathrm{Q}$ is clearly, resolved by Molecular Sieve $5 \mathrm{~A}\left(23^{\circ} \mathrm{C}\right)$, as shown in Figure 16b. The chromatogram of Figure 17a, obtained by the same Poropak $\mathrm{Q}$ column at a higher temperature $\left(85^{\circ} \mathrm{C}\right)$ than used previously (Figure 16a), shows the presence of additional peaks to those observed at a lower temperature ( $\mathrm{CO}$ and $\mathrm{CH}_{4}$ were not detected in products analyzed by Molecular Sieve 5A). The additional peaks belong to ethylene, unidentified (may be propylene), water, $\mathrm{HCN}$, and another unidentified one (probably an amine).

Product Gases from Catalytic Oxidation of HCN Evolved from Polyurethanes. The chromatographic resolution for nitric oxide (Figure 17b, Poropak $\mathrm{Q}, 21^{\circ} \mathrm{C}$ ) is only partial. It was, therefore, decided to examine the presence of $\mathrm{NO}_{x}$ (i.e., $\mathrm{NO}+\mathrm{NO}_{2}$ ) by an alternative method. This was done by degrading polymer films, and the evolved gas including $\mathrm{HCN}$ was catalytically oxidized with copper or its oxide. The lower oxides of nitrogen, if produced in this way, can be oxidized to nitrogen pentoxide in the gas phase by a strong oxidizing agent such as ozone. $\quad \mathrm{N}_{2} \mathrm{O}_{5}$ can then be absorbed in water where it hydrolyzes to nitric acid. The presence of $\mathrm{NO}_{3}{ }^{-}$ions can be quantitatively determined with a specific $\mathrm{NO}_{3}{ }^{-}$ion electrode. Details of this procedure were described by $\mathrm{D}$. Martini. ${ }^{8}$

The apparatus used for the degradation experiments is shown in Figure 6. The volatile products are mixed with a stream of ozonized air in a flask where oxidation of $\mathrm{NO}_{x}$ takes place to $\mathrm{N}_{2} \mathrm{O}_{5}$. Then the gases are passed through a dilute $\mathrm{NaNO}_{3}$ solution of known concentration. The flow rates of air, both through the ozonator and the degradation vessel, are controlled independently by suitable valves and measured. Finally, the increase in $\mathrm{NO}_{3}{ }^{-}$concentration is determined by the specific $\mathrm{NO}_{3}{ }^{-}$ion electrode.

Typical experimental conditions for this analysis were: polymer about $500 \mathrm{mg}, \mathrm{CuO}$ powder, about $300 \mathrm{mg}$; absorbing solution; initial concentration, $1 \times 10^{-4}-M \mathrm{NaNO}_{3}$ in water; ozonator, $0.85 \mathrm{a}$; flow pressure, 2 psi; flow velocity in ozonator, $114 \mathrm{~m} / / \mathrm{min}$; flow velocity through degradation vessel, 40 to $50 \mathrm{ml} / \mathrm{min}$; duration of experiment, $5 \mathrm{hr}$ at $300^{\circ} \mathrm{C}$.

In another set of experiments, the total amount of $\mathrm{HCN}$ which was evolved from the same amount of polymer and under the same experimental conditions as those given above was determined by absorbing $\mathrm{HCN}$ in $1-N \mathrm{NaOH}$ solution and measuring the $\mathrm{CN}^{-}$ion concentration with the specific $\mathrm{CN}^{-}$ion electrode. This data and the results obtained from the ozone oxidation experiments give an indication of the extent of the oxidation of $\mathrm{HCN}$ in the presence of $\mathrm{Cu}$ or its oxide to nitrogen oxides. The results were as follows: amount of HCN from aliphatic polyurethane, about $3.9 \times 10^{-5} \mathrm{~mol}$; amount of $\mathrm{NO}_{3}^{-}$obtained from ozone oxidation, about $1.2 \times 10^{-6} \mathrm{~mol}$.

These results are very surprising because they show that only about $3 \%$ of the total evolved $\mathrm{HCN}$ is oxidized to $\left(\mathrm{NO}+\mathrm{NO}_{2}\right)$ by $\mathrm{Cu}$ or its oxide.

We know from our experiments that practically all $\mathrm{HCN}$ produced from polyurethane is inhibited (i.e., oxidized) in the presence of excess $\mathrm{CuO}$. It can therefore be reasonably assumed in view of the results given in Table IV (second column), that $\mathrm{HCN}$ under our experimental conditions (moderate air velocity and small concentrations of $\mathrm{HCN}$ in the air stream) is oxidized by the catalyst largely 
to free nitrogen and only to a small extent to oxides of nitrogen.

Further, to verify the validity of the ozone oxidation results, a blank experiment (i.e., no catalyst) with the same amount of polymer was performed under identical conditions. A stream of ozonized air was mixed with the volatile degradation products; the gas mixture was passed through $\mathrm{NaNO}_{3}$ and the solution was analyzed as before. After the same reaction period, it was observed that practically no change took place in the measured initial $\mathrm{NaNO}_{3}$ concentration. This shows that the volatile products do not interfere with the oxidation method or the $\mathrm{NO}_{3}{ }^{-}$ion determination.

Catalytic oxidation of HCN. Determination of $N_{2}$. A number of experiments were carried out with a closed reaction system (see Figure 2). 300mg films of aliphatic polyurethane with different amounts of $\mathrm{Cu}$-dust dispersed in them were degraded at $300^{\circ} \mathrm{C}$ for three hours under a partial pressure of oxygen of $30 \mathrm{mmHg}$. He gas was added after degradation until $1 \mathrm{~atm}$ was reached. The gaseous products were analyzed under the same conditions as described under $\mathbf{C}(\mathrm{b})$. Results are shown in Figure 18. The amounts of $\mathrm{O}_{2}$ decrease in the closed system as thermal oxidative degradation proceeds. The amounts of $\mathrm{N}_{2}$ produced are a function of the amounts of $\mathrm{Cu}$ added. Thus HCN evolved from degraded polyurethane produces $\mathrm{N}_{2}$ in the presence of a catalyst, as does HCN evolved from $\mathrm{NaCN}$. Actually the amounts of $\mathrm{N}_{2}$ found indicate that in a closed vessel much more $\mathrm{HCN}$ is produced than in an open system. This is probably due to the presence of reaction products such as water which will induce further decomposition of the polymer by hydrolysis at $300^{\circ} \mathrm{C}$.

\section{DISCUSSION}

Appreciable quantities of hydrocyanic acid, $\mathrm{HCN}$, are evolved during thermal oxidative degradation of polyurethane in the range of temperatures from $200^{\circ} \mathrm{C}$ to $500^{\circ} \mathrm{C} .^{1}$ The kinetics and mechanism of this gas evolution was investigated in detail previously. ${ }^{1}$ Actual amounts of $\mathrm{HCN}$ produced in mol \% (one unit mol about $100 \%$ ) in air during $1 \mathrm{hr}$ exposure at $311^{\circ} \mathrm{C}$ are: aliphatic polyurethane $1 \%$ and aromatic polyurethane $0.4 \%$, or $2.84 \mathrm{~g}$ of
$\mathrm{HCN}$ from $284 \mathrm{~g}$ and $1.36 \mathrm{~g}$ of $\mathrm{HCN}$ from $340 \mathrm{~g}$ of polymer, respectively.

It must be pointed out that from the point of view of mechanism, $\mathrm{HCN}$ is only a minor product of the oxidative degradation of polyurethanes due to a minor side reaction. However, it is an important reaction because of its high toxicity.

Figures 8 to 14 show conclusively that metal and their powders as well as their decomposable compounds are effective in inhibiting HCN evolution. Copper, its oxides, and its compounds are the most efficient inhibitors. Especially potent inhibitors are the decomposable Cu-compounds, for they can be very finely dispersed in the polymers; also copper films deposited on polymer films show quite potent inhibiting powers. It is noteworthy that these films remain coherent during oxidation.

The main gaseous products obtained during the oxidation of polyurethanes at high temperatures are $\mathrm{CO}_{2}$ and $\mathrm{CO}$. For instance, after 30 minutes exposure to $30 \mathrm{mmHg}$ of $\mathrm{O}_{2}$ at $438^{\circ} \mathrm{C}$ the following gases were evolved in $10^{3} \mathrm{~m}_{\text {gas }}$ (i.e., in moles/unit mole of polymer) ${ }^{1}$ :

\begin{tabular}{lrcrccc}
\hline & $\mathrm{CO}_{2}$ & $\mathrm{C}_{2} \mathrm{H}_{4}$ & $\mathrm{C}_{2} \mathrm{H}_{6}$ & $\mathrm{H}_{2} \mathrm{O}$ & $\mathrm{CH}_{4}$ & $\mathrm{CO}$ \\
\hline Aliphatic & 807 & 95 & 39 & 15 & 46 & 411 \\
Aromatic & 1140 & 74 & 4 & 4 & 78 & 303 \\
\hline
\end{tabular}

$\mathrm{HCN}$ evolved in either gas is about 50 .

In the present paper, the following gases were found when the aliphatic polyurethane was oxidized at $300^{\circ} \mathrm{C}$ in air: $\mathrm{CO}_{2}, \mathrm{C}_{2} \mathrm{H}_{4}, \mathrm{C}_{3} \mathrm{H}_{6}\left(\right.$ ?), $\mathrm{H}_{2} \mathrm{O}, \mathrm{HCN}$, $\mathrm{H}_{2}$, and amine (?). The main products are $\mathrm{CO}_{2}$, $\mathrm{C}_{2} \mathrm{H}_{4}$, and $\mathrm{H}_{2} \mathrm{O}$. $\mathrm{CO}$ and $\mathrm{CH}_{4}$ were not found; if present, their quantities must be very small.

In the previous work ${ }^{1}$ a mechanism was proposed for the oxidative degradation of polyurethanes, as follows:

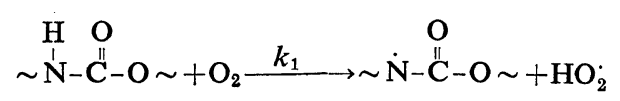

The following reaction will also be operative:

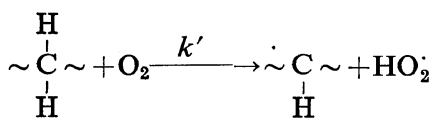

$\mathrm{CH}_{2}$ is usually adjacent to the NH-group. The subsequent reactions for reaction (1) and (1a) are analogous. The sequence of reactions for (1) is as follows: 


$$
\sim \dot{\mathrm{N}} \sim+\mathrm{O}_{2} \underset{k_{3}}{\stackrel{k_{2}}{\rightleftarrows}}\langle\text { Cage }\rangle
$$

Chain scission becomes permanent when fragments (i.e., chain radicals) escape from cages:

$$
\begin{aligned}
& \langle\text { Cage }\rangle \stackrel{k_{4}}{\rightarrow} \text { Fragments } \frac{\text { FAST }}{\sum k_{6}} \rightarrow \text { Other Products }
\end{aligned}
$$

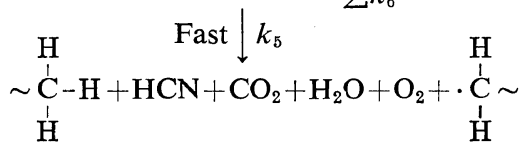

Reaction step $k_{5}$ is only a relatively small side reaction resulting from chain scission; many other products are formed by the simultaneous reaction steps $\sum k_{6}$. The above scheme was quantitatively evaluated; for the initial stages of $\mathrm{HCN}$ evolution, the following final rate equation for $\mathrm{HCN}$ evolution is obtained:

$$
\frac{\mathrm{d} m_{\mathrm{HCN}}}{\mathrm{d} t}=k_{\mathrm{exp}}\left[\mathrm{O}_{2}\right]
$$

$\mathrm{HCN}$ evolved from $\mathrm{NaCN}$ is decomposed catalytically by $\mathrm{Cu}$ or $\mathrm{CuO}$-powder (all $\mathrm{Cu}$ is converted in the presence of air to $\mathrm{CuO}$ at $300^{\circ} \mathrm{C}$ ). The amount of $\mathrm{HCN}$ decomposed depends on the flow or contact time of the oxidizing gas. If this is high (or long) relatively large amounts of $\mathrm{HCN}$ are left undecomposed. The flow rates were relatively slow in our experiments for the catalytic decomposition of $\mathrm{HCN}$ evolved from polyurethane. The concentrations of $\mathrm{HCN}$ in the oxidizing gas stream were small. Such conditions favor almost complete decomposition of $\mathrm{HCN}$.

The product gases from the decomposed $\mathrm{HCN}$ evolved from $\mathrm{NaCN}$ were found to be $\mathrm{N}_{2}, \mathrm{CO}_{2}$, $\mathrm{CO}, \mathrm{H}_{2} \mathrm{O}$, and $\mathrm{NO}_{2} ; \mathrm{N}_{2}$ was determined by a special procedure. It was found that at small flow rates (long contact times) the main gaseous product was $\mathrm{N}_{2}(c a .90 \%$ or more; this corresponds also to the conditions for $\mathrm{HCN}$ evolution from polyurethanes). At high flow rates the amounts of $\mathrm{N}_{2}$ decreased dramatically (to $c a .8 \%$ ).

Analysis of the catalytic decomposition products of $\mathrm{HCN}$ from polyurethanes (low flow rates, small $\mathrm{HCN}$ concentrations) showed that the products consisted mainly of $\mathrm{N}_{2}$ and small amounts of $\mathrm{NO}+\mathrm{NO}_{2}(c a .3 \%)$, possibly mixed with small amounts of other gases such as $\mathrm{H}_{2} \mathrm{O}, \mathrm{CO}$, and $\mathrm{CO}_{2}$; in addition gases are present due to the oxidation of polyurethane, leading to products other than HCN. Thus, it is seen that the catalytic oxidation of $\mathrm{HCN}$ evolved from $\mathrm{NaCN}$ yields under similar conditions the same products as the inhibition of $\mathrm{HCN}$ evolution from polyurethanes. This shows conclusively that the inhibition due to copper oxide is due to catalytic oxidation and decomposition of $\mathrm{HCN}$ evolved from the polymers and not to an alteration of the degradative oxidation mechanism.

The results presented here agree well with results for the catalytic decomposition of $\mathrm{HCN}$ gas or $\mathrm{HCN}$ evolved from $\mathrm{NaCN}$ by previous workers. ${ }^{2-4}$ Neumann and Manke ${ }^{4}$ found, with $\mathrm{CuO}$ as catalyst, that $\mathrm{N}_{2}$ was the predominant decomposition product, along with some nitrogen oxides; they also found $\mathrm{H}_{2} \mathrm{O}$ and $\mathrm{CO}_{2}$ in the product gases $\left(400^{\circ} \mathrm{C}\right)$. Sinozaki and $\mathrm{Hara}^{3}$ reported mainly $\mathrm{N}_{2}$ as the product with $\mathrm{CuO}$ as catalyst at $700^{\circ} \mathrm{C}$. All authors also found a small amount of a solid reaction product which they assumed to be a mixture of polymerized cyanuric acid $(\mathrm{HOCN})_{3}$ and cyamelide.

According to Neumann and Manke, ${ }^{4}$ the following exothermic reactions may take place for the oxidative and catalytic decomposition of $\mathrm{HCN}$ :

(1) $2 \mathrm{HCN}+5 \mathrm{O} \longrightarrow \mathrm{H}_{2} \mathrm{O}+\mathrm{N}_{2}+2 \mathrm{CO}_{2}$ $-317.12 \mathrm{kcal} / \mathrm{m}$

(2) $2 \mathrm{HCN}+7 \mathrm{O} \longrightarrow \mathrm{H}_{2} \mathrm{O}+2 \mathrm{NO}+2 \mathrm{CO}_{2}$ $-274.0 \mathrm{kcal} / \mathrm{m}$

(3) $2 \mathrm{NO}+\mathrm{O}_{2} \longrightarrow 2 \mathrm{NO}_{2}-40.5 \mathrm{kcal} / \mathrm{m}$

(4) $4 \mathrm{HCN}+10 \mathrm{NO} \longrightarrow 7 \mathrm{~N}_{2}+4 \mathrm{CO}_{2}+2 \mathrm{H}_{2} \mathrm{O}$ $-850.1 \mathrm{kcal} / \mathrm{m}$

If sufficient air is present and the contact time is long (i.e., small flow rates), then, reaction (1) will be predominant. If the gas velocities are high and the temperature low, reaction (2) will be the main one. These authors assume that as long as undecomposed $\mathrm{HCN}$ is still present, it reacts also according to step (4). They think that the oxidation proceeds via the imide (NH) as a transition product because they found small amounts of hydrazine, $\mathrm{N}_{2} \mathrm{H}_{4}$. Sinozaki's and Hara's ${ }^{3}$ formulations are similar. Zawadski and Liechtenstein ${ }^{4}$ also found mainly $\mathrm{N}_{2}, \mathrm{CO}_{2}$ and $\mathrm{H}_{2} \mathrm{O}$ when the air flow rate was small.

The mechanism of the catalytic decomposition of $\mathrm{HCN}$ can be tentatively formulated as follows (following largely Neumann and Manke's ${ }^{4}$ suggestions): 
H. H. G. Jellinek, A. Chaudhuri, and K. Takada

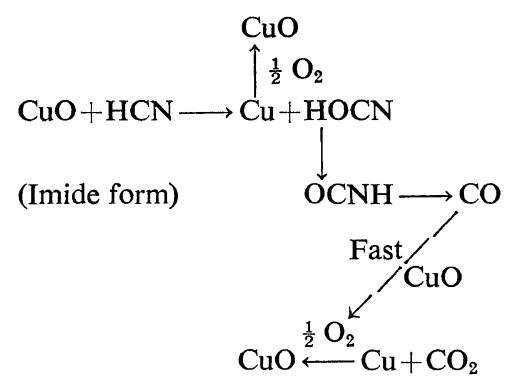

Acknowledgement. Thanks are due to NASA, Ames Research Center, for financial assistance which made this work possible.

\section{REFERENCES}

1. H. H. G. Jellinek and K. Takada, Toxic Gas Evolution from Polymers: Evolution of Hydrogen Cyanide from Linear Polyurethane, J. Polym. Sci., 13, 2709-2723 (1975); For Part II, H. H. G. Jellinek and K. Takada, ibid., 15, 2269-2288 (1977); K. Takada, Ph.D. Thesis, Department of Chemistry, Clarkson College, July 1976.

2. R. Hara and H. Sinozaki, Tohoku Teikoku Dai-<smiles></smiles>

gaku, Japan; Technology Reports, Sendai, V, 5 (2), 71 (1925).

3. H. Sinozaki and R. Hara, ibid., 6, 95 (1926).

4. B. Neumann and G. Manke, Z. Elektrochem. Angew, Phys. Chem., 35, 751 (1929). See also: J. Zawadzki and I. Lichtenstein, Rocznikow Chemji, 1926, 831.

5. C. S. Marvel and J. H. Johnson, J. Am. Chem. Soc., 72, 1674 (1950).

6. D. J. Lyman, J. Polym. Sci., 45, 49 (1960).

7. R. Newman and G. M. Badger, J. Am. Chem. Soc., 74, 3545 (1952).

8. R. D. Martini, Anal. Chem., 42, 1102 (1970). 